\title{
Conflict of interest in public health policy
}

\author{
Narada Warnasuriya \\ Department of Paediatrics, General Sir John Kotelawala Defence University, Sri Lanka \\ Correspondence: naradadw@gmail.com
}

DOI: https://doi.org/10.4038/jccpsl.v23i2.8123

Conflict of interest is defined as a set of circumstances that creates a risk that professional judgment or action regarding the primary interest is unduly influenced by the secondary interest. It is a situation that has the potential to undermine the impartiality of a person because of a clash between the person's self-interest and the public interest. Its primary interest may vary according to the context. For a clinician, it is the welfare of the patient. For a researcher, it is scientific integrity. For a medical teacher, it is the objectivity of education. For a public health policy maker, it is the health and wellbeing of the community. Conflict of interest has the potential to undermine the quality of patient care, the integrity of scientific investigation, the objectivity of professional education, and the quality, relevance, and equitable provision of health care. It could seriously undermine the public's trust in medicine. Links with industry and the corporate sector, with considerable financial gains and at times even professional advancement, is now recognized to be the most important secondary interest for clinicians, researchers, medical teachers, administrators and policy makers. This is a global phenomenon.

Conflict of interest in policy makers is recognized globally as a major negative determinant of public health policy. It is most detrimental when such conflicts are concealed. They have become more important in a context where non-communicable diseases (NCD) constitute the major burden of morbidity and mortality. The list of industries which poses the greatest risk has now expanded. It includes pharmaceutical, medical device, biotechnology, alcohol, tobacco, milk food, fast food, sweetened carbonated beverages, cosmetics and agro-chemical industries. Policy makers include politicians, administrators, technical experts, nominees of professional organizations and nominees from the civil society. All these categories are highly vulnerable to both legitimate and illegitimate links with above industries and the corporate sector, which lead to compelling conflicts of interest. At times, the linkage is with the institution itself which leads to institutional conflicts of interest. This is applicable to both professional and civil society organizations.

In a knowledge-based economy, academic and professional institutions are expected to work together with the industry and corporate sector in the creation, dissemination and utilization of knowledge. Publicprivate partnerships are considered a valuable mechanism for innovation and product development which benefit both individual and public health. At the same time, there are growing concerns that widely ranging financial ties with industry may unduly influence the professional judgment in respect of public health policy. There is a lack of clarity regarding the role of the corporate sector in public policy making especially in relation to prevention and control of NCDs.

There are three specific initiatives where Sri Lankan institutions have taken the lead which are worthy of mention in this context. The first was the development of a set of stringent guidelines for brand endorsement by professional organizations. They were drawn up by the expert committee on Food and Nutraceuticals of the Sri Lanka Medical Association (SLMA). This was done in a situation in which the SLMA's attention was drawn to an instance where a food product which was clearly not beneficial to the health of the consumer was endorsed by a professional association without independent verification of its contents. The 'Brand Endorsement Guidelines of the SLMA' were subsequently adopted by the Food Advisory Authority as a technical document to be used in their regulatory functions. It was commended in a special issue of SCN News on 'Nutrition and Business' published by the Standing Committee on Nutrition (SCN) of the United Nations. The second initiative was the inclusion of a module on 'Conflict of 
Interest' in the professionalism strand, which is compulsory for all postgraduate trainees of the Post Graduate Institute of Medicine (PGIM) before they receive board certification in their relevant specialization. The module is delivered as a half-day workshop in which small groups of trainees discuss case scenarios which depict varying conflicts of interest and present their conclusions on their prevention and/or mitigation in a plenary discussion. The WHO technical report on 'Addressing and Managing Conflicts of Interest' has referred to the above as a novel example of including conflict of interest as a specific topic in health professional training. The third and latest Sri Lankan initiative in this respect is the recently launched website of the Centre for Combating Tobacco (CCT), a joint venture of the Faculty of Medicine, University of Colombo, the expert committee on Alcohol and Tobacco of the SLMA, National Alcohol and Tobacco Authority (NATA) and Alcohol and Drug Information Centre (ADIC). Appropriately named 'Tobacco Unmasked', it is a bold and courageous step to expose all linkages, legitimate and illegitimate, between the tobacco industry and policy makers with a view to revealing potential conflicts of interest. It utilizes all publicly accessible information including the archives of the tobacco industry itself to reveal hitherto unknown links between policy makers and the tobacco industry, which may indicate the hidden motivation for their public stance on tobacco related policies and legislation. This measure, if successful in tobacco control, could prove to be trail blazer in all public health actions on other NCD risk factors.

As the excellent monograph on 'Conflict of Interest' by the Institute of Medicine of the National Academies of USA concludes, the goal of conflict of interest policies in public health is primarily to protect the integrity of professional judgment and to preserve public trust rather than to remediate bias or mistrust after they occur. Research on conflict of interest can provide a stronger evidence-base for policy design and implementation. The College of Community Physicians of Sri Lanka and the National Health Research Council should take note of this recommendation.

\section{References}

Institute of Medicine (US) Committee on Conflict of Interest in Medical Research, Education, and Practice; Lo B, Field MJ, editors. Conflict of interest in medical research, education and practice. Washington (DC): National Academies Press (US), 2009.

Available from: https://www.ncbi.nlm.nih.gov/books/ NBK22942/ doi: 10.17226/12598.

N.Warnasuriya. Brand endorsement by professional associations. Guest editorial: Chemistry in Sri Lanka, Institute of Chemistry Ceylon 2009; 26(1).

SCN News. Nutrition and business. How to engage? Standing Committee on Nutrition (SCN), United Nations System, No 39 late2011. ISSN 1564-3743.

WHO. Addressing and managing conflicts of interest in the planning and delivery of nutrition programmes at country level: report of a technical consultation. Geneva: World Health Organization, 2015.

Centre for Combating Tobacco,Faculty of Medicine,University of Colombo. Tobacco unmasked 2017.

Available from: http:/tobaccounmasked.lk/index.php? title=MainPage. 